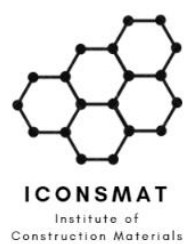

Content list available at ICONSMAT

Journal of Construction Materials

Journal homepage: www.iconsmat.com.au/publication
Article history:

Received 4 January 2021

Received in revised form

7 March 2021

Accepted 13 March 2021

Available online

20 March 2021

\title{
CO2 Capture and Storage Performance Simulation in Depleted Shale Gas Reservoirs as Sustainable Carbon Resources
}

\author{
Armin Shirbazo*1, Amin Taghavinejad ${ }^{1,2}$, Saber Bagheri ${ }^{3}$ \\ ${ }^{1}$ Department of Petroleum Engineering, Amirkabir University of Technology (Tehran Polytechnic), Tehran, Iran \\ ${ }^{2}$ Ahvaz Center for Petroleum Research, Ahvaz Faculty of Petroleum, Petroleum University of Technology, Ahvaz, Iran \\ ${ }^{3}$ Department of Petroleum Engineering, Faculty of Engineering, Islamic Azad University Central Tehran Branch \\ *Corresponding author: Armin Shirbazo, Researcher, Department of Petroleum Engineering, Amirkabir University \\ of Technology, Valiasr Avenue, Tehran, Iran. E: arminshirbazo@aut.ac.ir
}

\begin{abstract}
Underground carbon capture and sequestration (CCS) is a useful technique for separating this kind of greenhouse gas from atmosphere and store it under the surface of the earth. As a matter of fact, $\mathrm{CO} 2$ can be transferred to underground petroleum reservoirs which are initially contained oil and gas, or aquifers which are initially saturated with water. This kind of CCS takes place using an injection well which is drilled from surface to the target underground bedrocks. A shale gas reservoir (SGR) is a type of petroleum gas reservoir in which natural gas is stored in ultra-tight pores of the shale rock. In this study, a flow modeling analysis in SGR with a multi-stage fractured horizontal well (MSFHW) is conducted using numerical simulation. In this shale layer, a horizontal well is drilled and several transverse hydraulic fractures, for increasing the flow efficiency between the well and porous medium, are created. The studied SGR - a depleted reservoir acting as a macroscopic sustainable material for the CCS - is initially saturated with methane gas, and carbon dioxide is required to be injected for the storage. The most outstanding results of this study is about sensitivity analyses for SGR permeability with different conditions of gas adsorption and stress-dependent permeability which are from important features of SGRs. The results show a minor reduction in cumulative gas injection due to the effect of stress-dependent permeability in all measures for reservoir permeabilities. Furthermore, gas sorption shows a considerable positive correlation with $\mathrm{CO} 2$ storage response in high-permeability SGR and a minor increasing effect on SGRs with lower permeability values.
\end{abstract}

DOI: $10.36756 /$ JCM.si1.3 C2021 Institute of Construction Materials

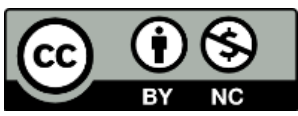

\section{Keywords}

Carbon capture and storage, Shale gas reservoir, Adsorption, Reservoir simulation, Sustainable resources 


\section{Introduction}

Carbon capture and storage or carbon capture and sequestration (CCS) is the process of seizing carbon dioxide (CO2) formed during various fields related to the energy industry and reserving it in an isolated space from atmosphere such as underground in order to prevent this greenhouse gas from entering the atmosphere. Different CCS technologies have been introduced in recent years to capture carbon dioxide efficiently and store them by various facilities or methods under ground's surface as a sustainable resource of sequestrated $\mathrm{CO} 2$. Recent high-tech facilities have this ability to capture around $90 \%$ of the whole produced CO2 [1].

Carbon dioxide emission has influenced different types of industries such as cement plants, coal power plants, etc. Also, carbon dioxide may decompose into oxygen and carbon nanoparticles and affect different materials and constructions [2]. Some industries have been benefited from using carbon capture and they are now being considered for fulfilment in the construction industry especially in the cement factories. The application in the construction industry can go further to steel manufacturing industries. This matter requires a high amount of investment and due to this reason $\mathrm{CO} 2$ capturing techniques have not shown remarkable development in this scheme [3]. Also, the CO2 storage after the capturing process is one of the difficulties encountered in the industry [4].

One of the methods to capture the $\mathrm{CO} 2$ in a proper and safe way is related to petroleum industry. As a matter of fact, oil and gas reservoirs, especially in their depleted forms, are good candidates for underground $\mathrm{CO} 2$ storage far away the surface of the earth via injection wells. Many researchers have studied on this purpose investigating various considerations and technologies for having a better control over $\mathrm{CO} 2$ storage processes [5]. Among different types of petroleum reservoirs, shale gas reservoirs (SGRs) which are of natural gas unconventional resources, mostly methane $(\mathrm{CH} 4)$, has become popular for CCS within recent decades [6]. Widespread nature of SGRs dimensions and also high capacity of CO2 adsorption in shale rocks' surface make this kind of natural gas reservoir a favorable spot for CO2 storage [7].

SGRs are of unconventional reservoirs which are different with conventional petroleum reservoirs in both rock and fluid properties and also exploitation methods [8]. Petroleum reservoirs are porous rocks containing hydrocarbons plus connate water. In fact, reservoir rocks comprise rock volume and pore volume. To quantify amount of the pore volume in a reservoir rock, porosity degree can be defined - the ratio of pore volume to total volume of the porous medium (reservoir rock). Also, the ability of fluid conductivity in a reservoir rock is evaluated by permeability. In fact, permeability is a measure for ability of a porous medium for fluid flow relating fluid velocity to pressure gradient whose unit is $\mathrm{m}^{2}$ in the metric system or Darcy or milli-Darcy in oilfield system. Inherently, unconventional reservoirs such as SGRs have a low to ultra-low permeability nature compared to conventional reservoirs. In addition, most of the SGR rock layers are naturally fractured. Naturally fractured reservoirs (NFRs) have two distinct porous zones matrix and fracture media. On the one hand, rock matrix has higher porosity than the fracture, but on the other hand natural fracture (NF) has a significant higher amount of permeability compared to the matrix medium. A schematic view of naturally fractured SGR is shown in Figure 1. This figure depicts real and dual porosity model naturally fractured SGR schemes. It should be noted that dual porosity model is one of the primary models for taking into account NFs in flow modeling of NFRs. This model considers NFs that are distributed in rock space uniformly surrounded by matrix blocks. Numerical simulation in this study takes advantage of dual porosity model for naturally fractured SGR flow modeling. 


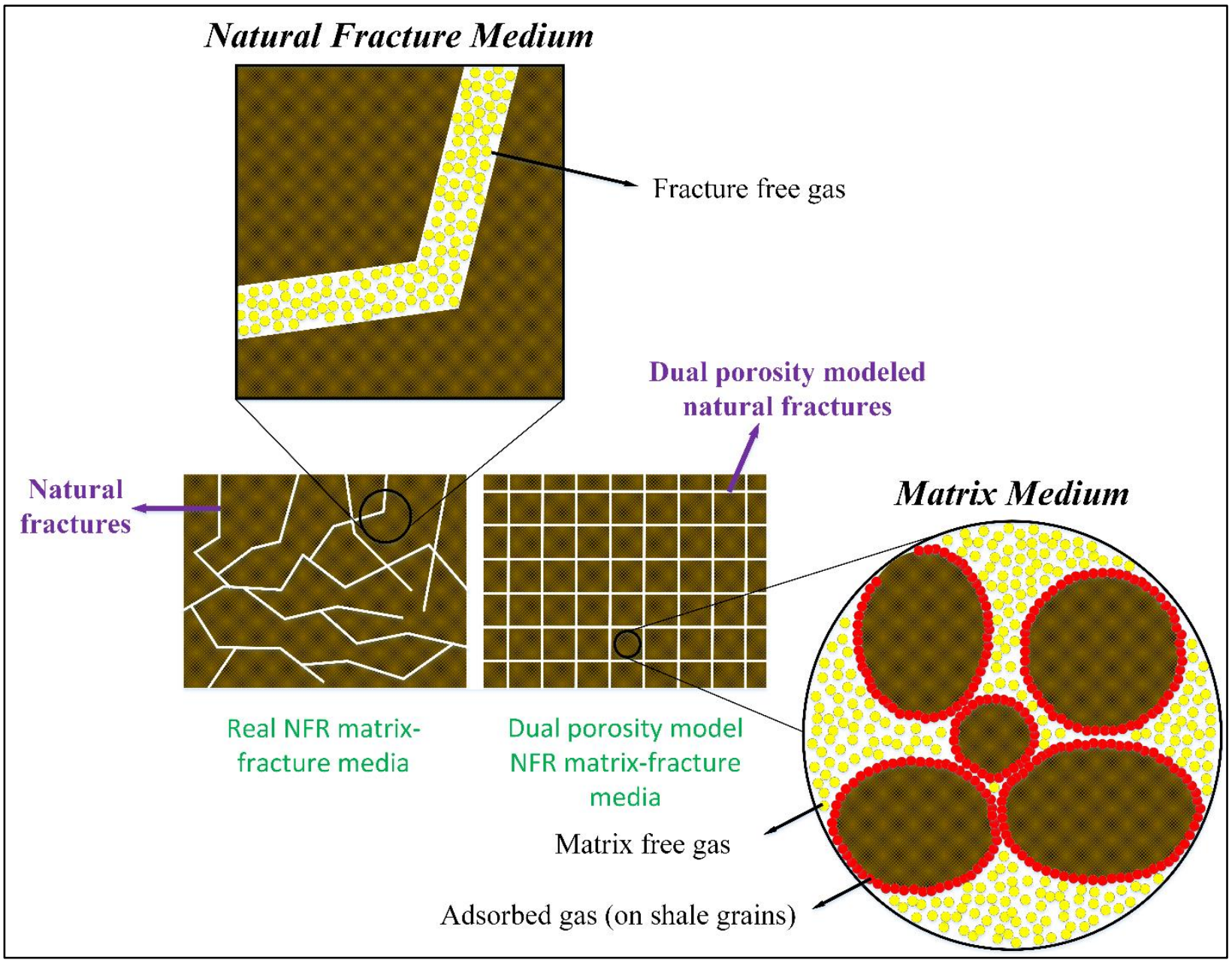

Figure 1 Schematic view of naturally fractured SGR rock comprising matrix and fractures containing free and adsorbed gas (visualized from [9])

As it is depicted in Figure 1, natural gas in shale reservoirs is in two forms - free gas (similar to conventional gas reservoirs) and adsorbed gas (unconventional form of natural gas on shale rock matrix grains). Commonly, adsorbed gas is considered in flow modeling in shale strata using Langmuir isotherm model $[8,10]$ which contributes the amount of adsorbed gas to the system pressure (reservoir pressure in our case). The more reservoir pressure is, the more capacity for gas adsorption will be [11].

Furthermore, petrophysical properties of shale strata are mostly stress-dependent [8]. In fact, by increasing effective stress on these deep underground rock layers - following production of hydrocarbons from them and their depletion - pore throats size will be shrunk. Consequently, porosity and permeability of them will be decreased [12]. Also, by implementing fluid injection into these reservoirs and decreasing net stress on these bedrocks and increasing pore pressure, porosity and permeability may have an increase [13]. 
To create more permeable pathways for fluid transport in tight and shale strata, using multi-stage fractured horizontal wells (MSFHWs) has been a suitable option for the operators for a decade. To have an MSFHW in practice, a high-pressure fluid is injected to the reservoir in different stages to create a highly conductive path through the reservoir into the horizontal well. Taking advantage of MSFHWs for development of shale gas fields is an inevitability. As a matter of fact, this is the only present method for having economic recovery from these reservoirs [14]. In other words, not having MSFHWs in shale fields is equal to no recovery in these petroleum resources. In other words, hydraulic fractures (HFs) stimulate the reservoir rock to increase reservoir rock permeability and furtherly amount of production/injection rate. In this regard, reservoir rock zones in the vicinity of HFs can be called stimulated rock volume (SRV), and the reservoir zone far away the MSFHW is named unstimulated rock volume (USRV).

One of the serious problems of $\mathrm{CO} 2$ storage in depleted gas reservoirs is the remoteness between the reservoir and the CO2-producing equipment. This distance between the reservoir and the equipment provides a space in which a number of $\mathrm{CO} 2$ capturing facilities can be installed connecting $\mathrm{CO} 2$-producing equipment and geological target. These capturing facilities include different types such as pre-combustion, post-combustion, and natural gas processing [4]. Also, some factors specify that a reservoir can be used for CO2 disposal or not, for instance the existence of pipelines and not being located in inopportune areas such as deep seas [15]. As it is pointed out by several studies [16,17], higher adsorption capacity of CO2 than the $\mathrm{CH} 4$ determines that $\mathrm{CO} 2$ injection in SGRs can displace $\mathrm{CH} 4$ in the reservoir which can call this process a method of enhanced gas recovery (EGR). Also, their results showed a good chance for further geologic storage of $\mathrm{CO} 2$ in depleted SGRs as part of the EGR process. Regarding the study of Huang et al. [18], by considering shale formations composed of two main parts - organic and inorganic matrices, they demonstrated that CO2 storage capacity of SGR can be extremely decreased if dispersed distribution of kerogen (organic matrix) is taken into account. Also, they found total organic carbon (TOC) and CO2 injection rate have obvious effects on the performance of $\mathrm{CO} 2$ injection. If kerogen is defined implicitly in the model, TOC and injection rate have a positive correlation with $\mathrm{CH} 4$ recovery and $\mathrm{CO} 2$ storage. Also, in case kerogen is explicit in the model, TOC and gas injection rate are negatively correlated with $\mathrm{CH} 4$ recovery and storage capacity of $\mathrm{CO} 2$. In addition, Sun et al. [19] investigated the impact of temperature, pressure, humidity and different gas types on isothermal adsorption and desorption of shale gasses to validate the possibility of augmenting shale gas recovery by $\mathrm{CO} 2$ injection. They concluded that adsorption ability for methane rises by decreasing temperature and humidity and increasing pressure in some values. Furthermore, the trend of adsorption ability for different gas types is $\mathrm{CO} 2>\mathrm{CH} 4>\mathrm{N} 2$, while for their desorption capacity is $\mathrm{CH} 4>\mathrm{CO} 2>\mathrm{N} 2$.

CCS in shale formations needs proper mathematical flow modeling. As reported by Schaef et al. [20], there is a meaningful relation between important shale rock minerals and adsorbing gasses ( $\mathrm{CH} 4$ and $\mathrm{CO} 2)$. Thus, reinforcement condensation of $\mathrm{CO} 2$ resulted by desorption on clay surface is observed under supercritical conditions, and a linear sorption profile appears for $\mathrm{CH} 4$. Also, they experimentally analyzed $\mathrm{CO} 2-\mathrm{EGR}$ as an economic chance that requires proper methane recovery. Finally, they stated that it is necessary to have a strategy to optimize injection rates and volumes for maximum $\mathrm{CH} 4$ desorption and $\mathrm{CO} 2$ retention at a field-scale level. Raza et al. [21] constructed a numerical simulation model to pay more attention to effect of SGRs' residual gas on the capacity, injectivity, reservoir pressurization, and trapping mechanisms of storage zones. Their results showed that the efficiency of the storage is related to the quantity of residual gas in porous media. In other words, the best candidates for this aim are reservoirs with lower residual fluids. They also indicated that a direct connection is established between remaining gas and the capillary 
trapping, while an opposite relationship stands for the stability of the injection rate, structural trapping, and dissolution trapping versus the storage capacity. White et al. [22] developed a novel numerical simulator to take into account $\mathrm{CO} 2$ usage and storage in partially depleted porous media, actually in deep saline reservoirs. They provided an applicable device for studying and realizing such processes, regarding the complicated coupled procedures occurred by the injection of $\mathrm{CO} 2$ into petroleum reservoirs. Boosari et al. [23] studied on $\mathrm{CO} 2$ storage and relating technologies providing useful recommendation with respect to the complex phenomena modeled mathematically. They concluded that although a shale reservoir has ultra-tight pore sizes, considerable amount of $\mathrm{CO} 2$ can be adsorbed on shale fracture surfaces. Also, some factors such as buoyancy, heterogeneity of shale reservoirs properties and existence of formation water are crucial for proper $\mathrm{CO} 2$ storage modeling. Lekic et al. [24] compared $\mathrm{CO} 2$ storage capacity concluded by two analytical correlations compared with total storage capacity obtained from simulation results. Their results verified analytical approach showing that - depending on the depth - mass of the injected CO2 is twice of the mass of produced $\mathrm{CH} 4$.

Several research studies investigated various aspects of CCS including multiple criteria for developing a reliable system for this aim. Winter and Bergman [25] investigated the disposal capacity of depleted reservoirs gas wells in the United States. They deduced that the total underground capacity available for instant disposal is minor compared to the considerable amounts of annual power plant CO2 emissions. Aminu et al. [26] provided the fundamental scheme for development of CO2 storage by making discussion on some other aspects of CCS in shale gas deposits. They investigated the vital basis for storage site selection contained some practical and impractical points and also made a comparison between $\mathrm{CO} 2$ movement during and after the injection process. They believed that different challenges and uncertainties associated with further development such as storage capacity and also verification and monitoring of CO2 during and after injection should be distinguished to speed up the progress of the CO2 storage technology. Chen et al. [27] performed a study to evaluate the influence of some factors on carbon storage capacity. By using analytical modeling, they reached a solution for determining wellbore pressure, and calculated the required time for $\mathrm{CO} 2$ injection. They found that inadequate $\mathrm{CO} 2$ storage capacity will be available in case $\mathrm{HFs}$ conductivity is small. Also, higher $\mathrm{CO} 2$ storage potential can be achieved by raising the number of HF stages and providing higher permeability in SRV zone.

The numerical modeling and simulation of shale reservoirs exploited by MSFHWs is differed from nonhydraulically fractured reservoirs. Regarding some of the related works $[14,28,29]$, defining a MSFHW in a numerical simulation model can be done using local grid refinement (LGR). LGR is a proper method for modeling HFs in which fractures are defined in the system by their explicit values for permeability and width as sub-grids of the original grid blocks of the model. As a matter of fact, fractures can be defined in this method by determining size of grid cells (describing the geometry of fractures in $x, y$ and $z$ directions) alongside a well and include all specifics of the reservoir such as porosity, permeability, heterogeneity and other parameters. By defining HFs in the model using LGR method for near-wellbore grids, emerged complexity of the fluid flow between HFs and porous media due to the flow regime change in proximity of HFs can be recorded [30]. The LGR method is easy to apply and can also account for different HF's properties and illustrates fracture geometry explicitly to simulate the precise performance of reservoir productivity or injectivity [31]. However, it has some drawbacks worth mentioning. In LGR, rectangular fracture shape is considered in the modeling, although HFs have an elliptical shape in practice. Hence, it may cause some inaccuracies in the modeling and can be mitigated using some considerations like defining amalgamated LGRs in different layers to change the simple rectangular shape to a more real fracture shape 
[32]. Also, small grid cell size of a model with LGR may lead to long simulation run time. Moreover, by using LGR, it is difficult to add or modify properties of different fractures segments through the simulation [28]. HFs in the numerical model of this study are defined using LGR method.

The objective of this study is to investigate CO2 storage response via an MSFHW in a synthetic SGR. Amount of total $\mathrm{CO} 2$ injection as a measure of $\mathrm{CO} 2$ storage performance and its variation with shale permeability and its stress sensitivity, shale porosity, and also gas sorption capability of shale rock are studied in this work.

\section{Model Description}

A 3D numerical model is constructed for numerical calculations with finite difference method using commercial reservoir simulator Eclipse. Simulation study is CO2 injection into an SGR with large lateral area. A 5-stage MSFHW is located in the center of reservoir volume and $\mathrm{CO} 2$ injection takes place through it. SGR is considered to be naturally fractured and modeled with dual porosity model. Reservoir is initially saturated with low-pressure $\mathrm{CH} 4$, and $\mathrm{CO} 2$ is designed to be injected for 200 days. Ability of gas sorption is activated in this synthetic SGR model and two important sensitivity analyses are studied. Analyses are run for investigating the effect of results (total $\mathrm{CO} 2$ injection) sensitivity to shale permeability, shale stressdependent permeability, shale porosity, and shale rock gas adsorption ability.

Numerical simulation study can be performed by defining a reservoir model with specified number of grid blocks. To do so, a reservoir model with rectangular horizontal shape is considered with a specific reservoir thickness (declared in Table 1). Total number of numerical grid blocks in which solution of the governing equations are obtained is 79,19 , and 11 in $x, y$, and $z$ directions, respectively. Before running the simulation, reservoir pressure is considered equal to $800 \mathrm{psia}$, and also it is assumed that pore volume of the reservoir rock is saturated completely with methane gas. Also, LGR causes grid blocks in $\mathrm{x}$ and $\mathrm{y}$ directions to vary in size logarithmically, although grid blocks in z direction have constant size of 20 feet. The simulation fluid model is compositional and all needed property values for components ( $\mathrm{CO} 2$ and $\mathrm{CH} 4$ ), such as critical temperature and pressure, are from [33]. In the compositional model, Peng-Robinson equation of state is used for fluid modeling.

CO2 injection in this study takes place under the constant bottomhole pressure constraint. For all analyses, this constant value is equal to 4000 psia.

Table 1 Base reservoir model data

\begin{tabular}{|l|l|}
\hline Property & Value \\
\hline Initial pressure & $800 \mathrm{psia}$ \\
\hline Reservoir temperature & $160^{\circ} \mathrm{F}$ \\
\hline$X$ dimension & $4926.58 \mathrm{ft}$ \\
\hline Y dimension & $4747 \mathrm{ft}$ \\
\hline$Z$ dimension (reservoir thickness) & $220 \mathrm{ft}$ \\
\hline Matrix porosity for USRV & 0.06, fraction \\
\hline Matrix porosity for SRV & 0.1, fraction \\
\hline Fracture porosity for USRV & 0.005, fraction \\
\hline
\end{tabular}




\begin{tabular}{|l|l|}
\hline Fracture porosity for SRV & 0.01, fraction \\
\hline Matrix horizontal permeability for USRV & $0.01, \mathrm{md}$ \\
\hline Matrix horizontal permeability for SRV & $0.1, \mathrm{md}$ \\
\hline Fracture horizontal permeability for USRV & $20, \mathrm{md}$ \\
\hline Fracture horizontal permeability for SRV & $60, \mathrm{md}$ \\
\hline Matrix block size & $100, \mathrm{ft}$ \\
\hline Fracture-matrix transfer shape factor & $0.0012,1 / \mathrm{ft}^{2}$ \\
\hline Number of hydraulic fracture stages & 5 \\
\hline Hydraulic fracture permeability & $20000, \mathrm{md}$ \\
\hline Hydraulic fracture porosity & 0.3, fraction \\
\hline Matrix block size & $100, \mathrm{ft}$ \\
\hline Rock compressibility (at 3000 psia reference pressure) & $4 \mathrm{E}-6, \mathrm{psia}{ }^{-1}$ \\
\hline Initial CH4 composition for matrix & $1, \mathrm{fraction}$ \\
\hline Initial CO2 composition for matrix & $0, \mathrm{fraction}$ \\
\hline Langmuir volume for CH4 & $0.45 \mathrm{MSCF} / \mathrm{ton}$ \\
\hline Langmuir volume for CO2 & $0.9, \mathrm{MSCF} / \mathrm{ton}$ \\
\hline Langmuir pressure for CH4 & $400, \mathrm{psia}$ \\
\hline Langmuir pressure for CO2 & $200, \mathrm{psia}$ \\
\hline Bottomhole pressure & $4000, \mathrm{psia}$ \\
\hline
\end{tabular}

Table 1 shows all synthetic data used for construction of the reservoir model for numerical simulation. In this SGR model, porosity and permeability values for shale matrix and NFs are determined in Table 1 for both SRV and USRV zones. Moreover, defined HFs in simulation model are narrow grid blocks created by LGR method with a width equal to 0.016 feet and constant permeability of 20000 md. HFs are fully developed in z-and y-directions. Figure 2 shows a 3D schematic of the numerical model grid blocks. Legend of this figure shows grid size for matrix medium varies in $x$ direction logarithmically. On the one hand, rock permeabilities in $\mathrm{x}$ and $\mathrm{y}$ directions (horizontal permeabilities) are equal with each other in this reservoir model. On the other hand, vertical permeability (permeability in z direction) is one tenth of horizontal permeability for all reservoir grid blocks. 


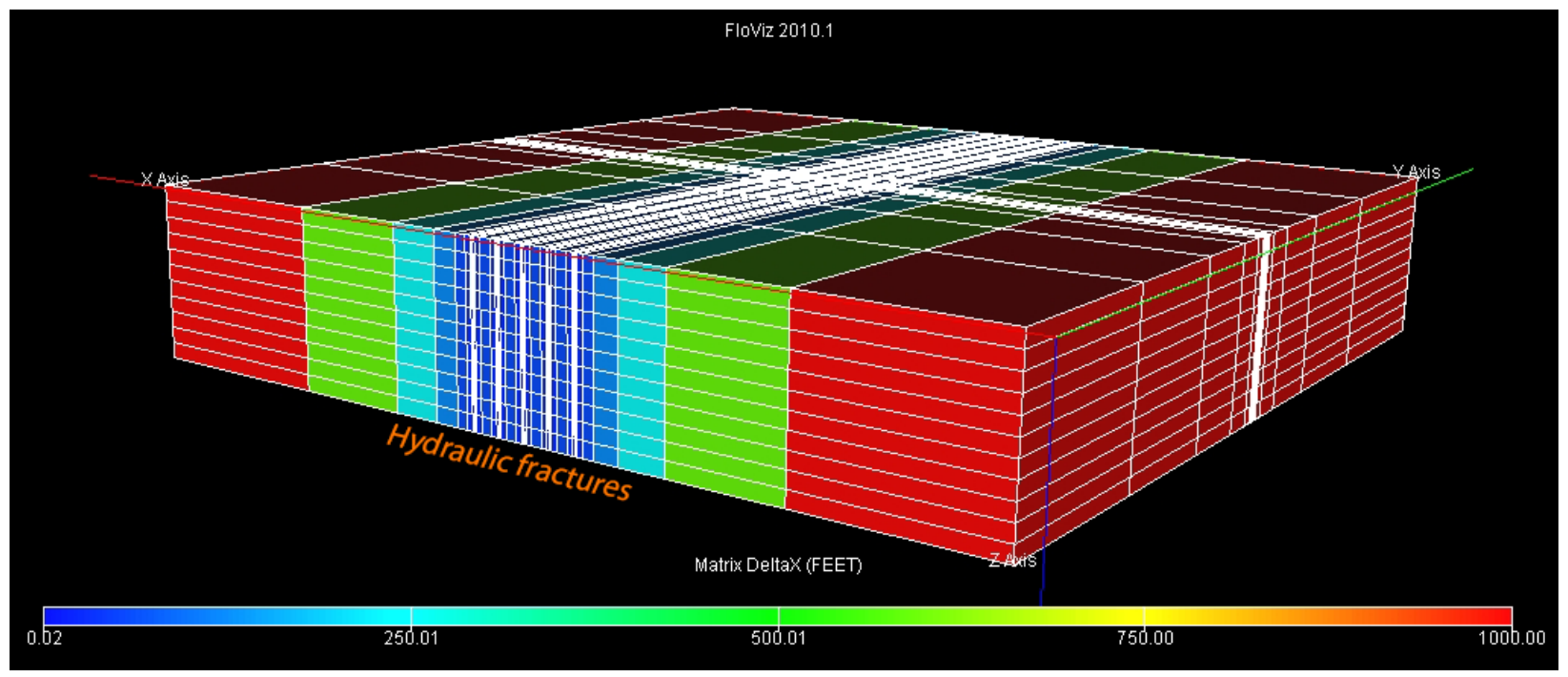

Figure 2 Schematic of base case SGR numerical model having a 5-stage MSFHW

According to the Kazemi dual-porosity reservoir model [34], two important parameters are defined to describe inter-porosity flow (flow between matrix and fracture media) - matrix block size and shape factor. Shape factor determine the strength of the inter-porosity flow and is a function of the matrix block size. The relation between these two parameters is as [34]:

$$
\sigma=\frac{12}{I_{m}^{2}}
$$

Where $\sigma$ is shape factor, $1 / \mathrm{ft}^{2}$, and $I_{m}$ is matrix block size, $\mathrm{ft}$. These two parameters are defined in the model as shown in Table 1.

To analyze the considered SGR as a bulk-scale sustainable material for storing CO2 under the earth's surface, its stress-dependent permeability and gas sorption features are studied. As a matter of fact, it is supposed to see the importance of these two important features of SGRs for a CCS operation. In this numerical model, two important analyses are designed to be studied. In both cases, sensitivity of total CO2 injection to permeability of the rock is analyzed. In addition, effect of presence of stress-dependent permeability in the first case, and effect of presence of gas adsorption in the second case are analyzed as well. Table 2 below demonstrates how rock properties vary for both analysis cases in this study.

Table 2 Rock property values for sensitivity analyses

\begin{tabular}{|l|l|l|}
\hline Case & Property & Value \\
\hline$\# 1 \quad$ Presence of stress- & Permeability & $k_{\text {base }}, 0.1 \mathrm{k}_{\text {base, }}, 10 \mathrm{k}_{\text {base }}$ \\
\cline { 2 - 3 } $\begin{array}{l}\text { dependent permeability } \\
\text { phenomenon }\end{array}$ & Porosity & $\phi_{\text {base, }} 0.5 \phi_{\text {base }}$ \\
\hline $\begin{array}{l}\text { \#2 Presence of gas adsorption } \\
\text { phenomenon }\end{array}$ & Permeability & $k_{\text {base, }} 0.1 \mathrm{k}_{\text {base, }}, 5 \mathrm{k}_{\text {base }}$ \\
\hline
\end{tabular}


In case 1 , stress-dependent permeability is modeled using cubic law of porosity variation with effective stress on shale layers [35]:

$$
\frac{\mathrm{k}}{\mathrm{k}_{0}}=\left(\frac{\phi}{\phi_{0}}\right)^{3}
$$

Where $k$ and $\phi$ are stress-dependent permeability and porosity, respectively, and $k_{0}$ and $\phi_{0}$ are initial values of permeability and porosity, respectively.

Stress-dependent porosity is explicitly defined for the model as the following plot (Figure 3) which describes porosity change versus pore pressure of the SGR.

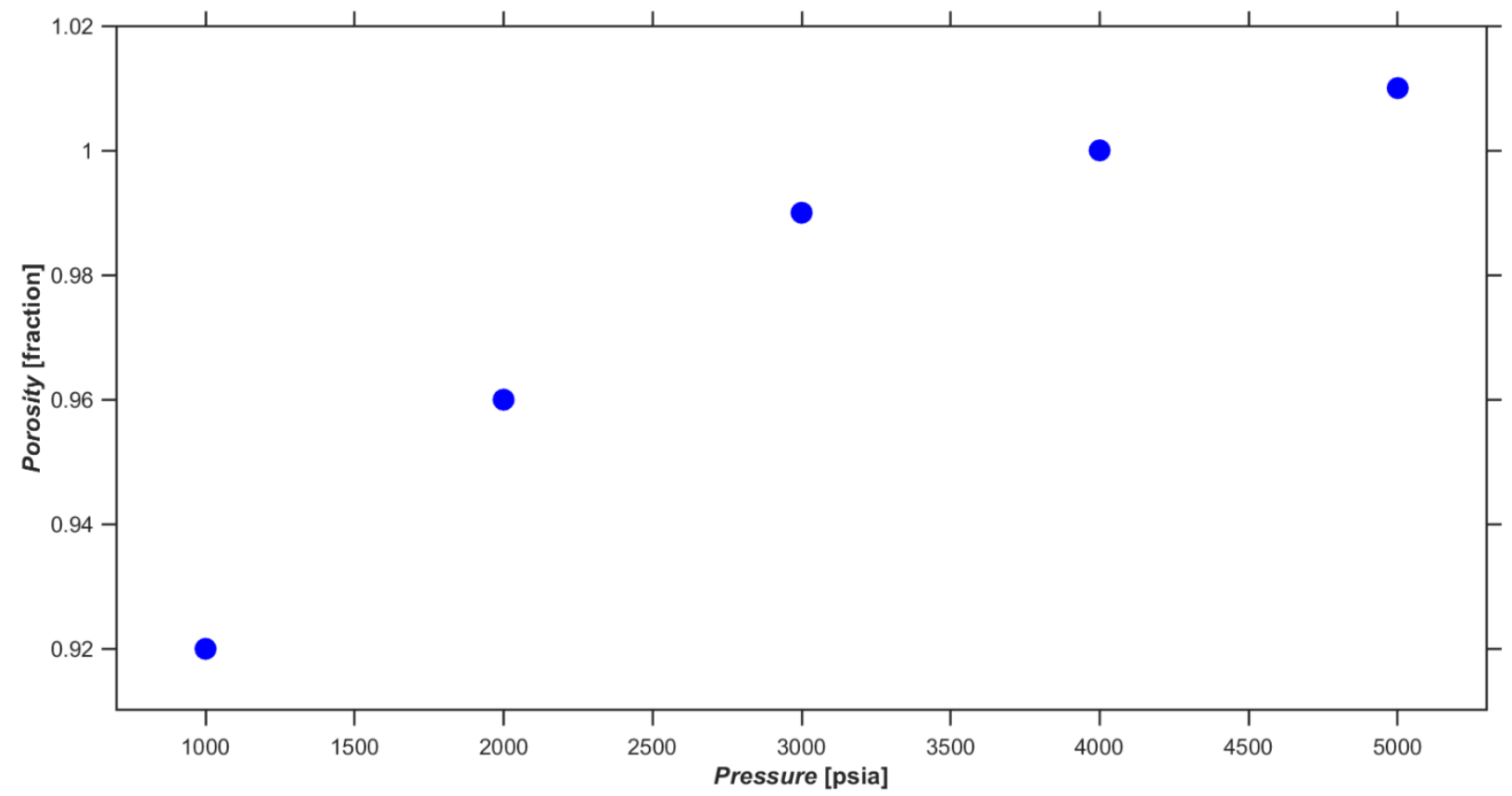

Figure 3 Changing SGR porosity versus pore pressure of the numerical reservoir model

As it is declared in Table 2, in the first case the sensitivity of total volume of injected $\mathrm{CO} 2$ is analyzed with respect to variation in permeability and considering that the SGR permeability being or not being stressdependent. Also, the results are obtained for the case with porosity values with half of base case model porosities.

In case 2, effect of gas adsorption/desorption is studied during the CO2 injection to the base case SGR. Volume of adsorbed/desorbed gas, regarding the Langmuir model [10], is taken into account in numerical calculations as the following formulation:

$$
V=\frac{V_{L} P}{P+P_{L}}
$$


Where, $\mathrm{V}$ is the volume of adsorbed/desorbed gas, MSCF/ton, $\mathrm{P}$ is system pressure, $\mathrm{psia}$, $\mathrm{V}_{\mathrm{L}}$ is Langmuir volume of adsorbing gas, MSCF/ton, and $\mathrm{P}_{\mathrm{L}}$ is Langmuir pressure of the adsorbing gas, psia. Amounts of $\mathrm{V}_{\mathrm{L}}$ and $\mathrm{P}_{\mathrm{L}}$ for both $\mathrm{CO} 2$ and $\mathrm{CH}_{4}$ in the model are as shown in Table 1.

Now by knowing the details of the model, results of the two designed analyses can be achieved.

\section{Results}

The most outstanding outputs of simulation study on the CO2 storage process in the synthetic SGR model are presented in this part. Performance of the CCS is analyzed by the amount of total injected CO2 to the reservoir as well as some other indicators such as reservoir pressure and reservoir gas in-place.

Running the simulation model of CO2 storage in the SGR base case model for 200 days leads to the following results for total $\mathrm{CO} 2$ injection, total gas in-place, $\mathrm{CO} 2$ injection rate, and field pressure depicted in Figure 4. This figure shows that total $\mathrm{CO} 2$ injection, total gas in-pace, and total field pressure increases with injection time (Figure 4 - a, b, and c, respectively). Also, as it is depicted in Figure 4-d, flow rate of CO2 injection will have a decline during the injection period. Increasing trends in Figure $4-a, b$, and $c$ are due to the increase in amount of $\mathrm{CO} 2$ injection with time. Regarding the Figure 4-d, gas injection rate cannot remain constant and will vary with time because of constant bottomhole pressure of injection. Also, the decreasing trend in Figure 4- $d$ is because of this issue that SGR model is limited in boundaries and injection rate would not increase continuously.
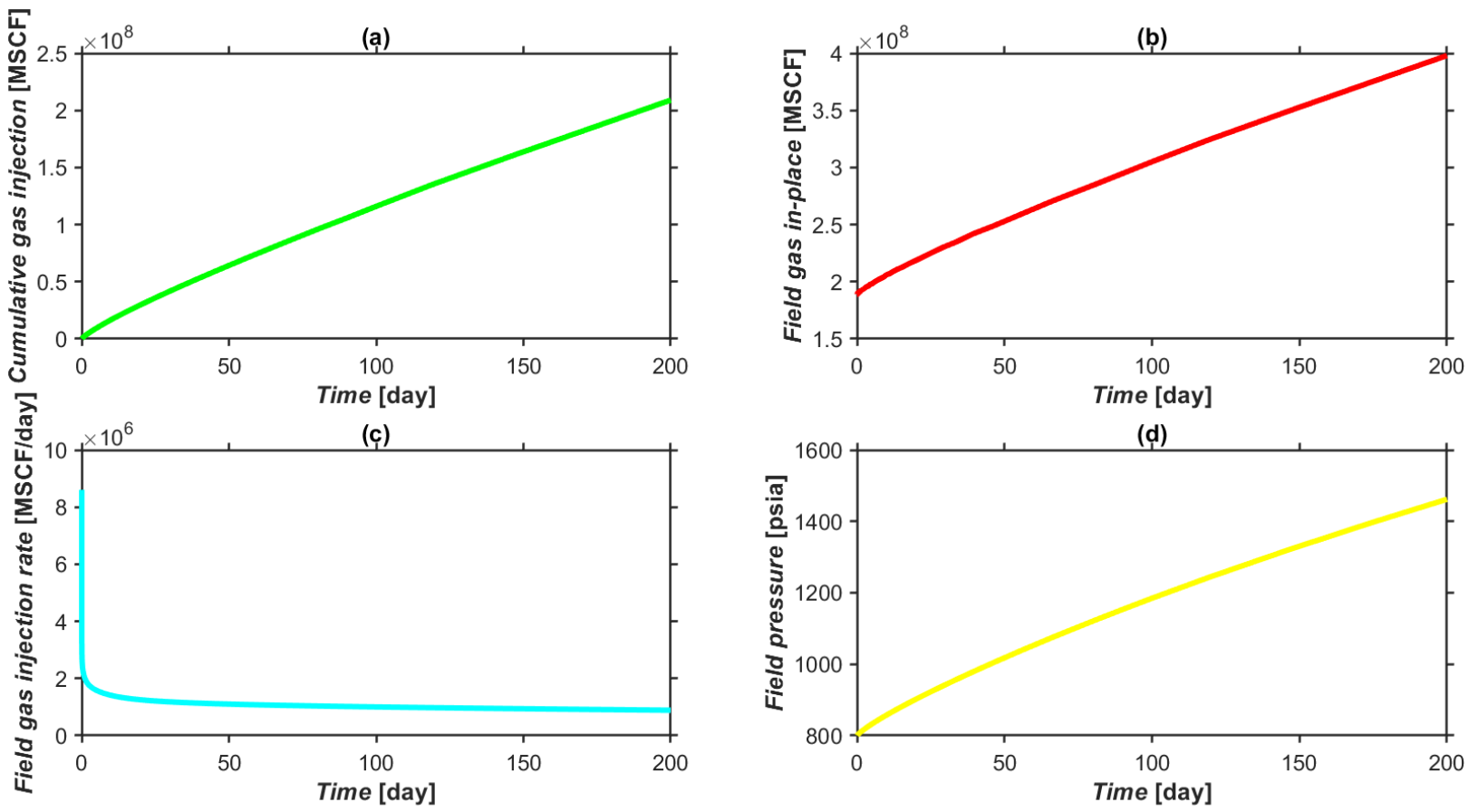

Figure 4 Base case SGR field cumulative gas injection (a), gas in-place (b), gas injection rate (c), and pressure $(d)$ results 
Figure 5 shows the result for the base case model with variation in permeability values and also sensitivity analysis for stress-dependent permeability. In this figure, it can be inferred that an increase in reservoir permeability values, for both matrix and NF media of SRV and USRV zones, increases the cumulative CO2 injection. This sensitivity is more obvious in higher reservoir permeabilities than the low-permeability values. In addition, effect of stress-dependent permeability in this figure reveals that this effect in all values for reservoir permeabilities causes a slight decrease in cumulative gas injection.

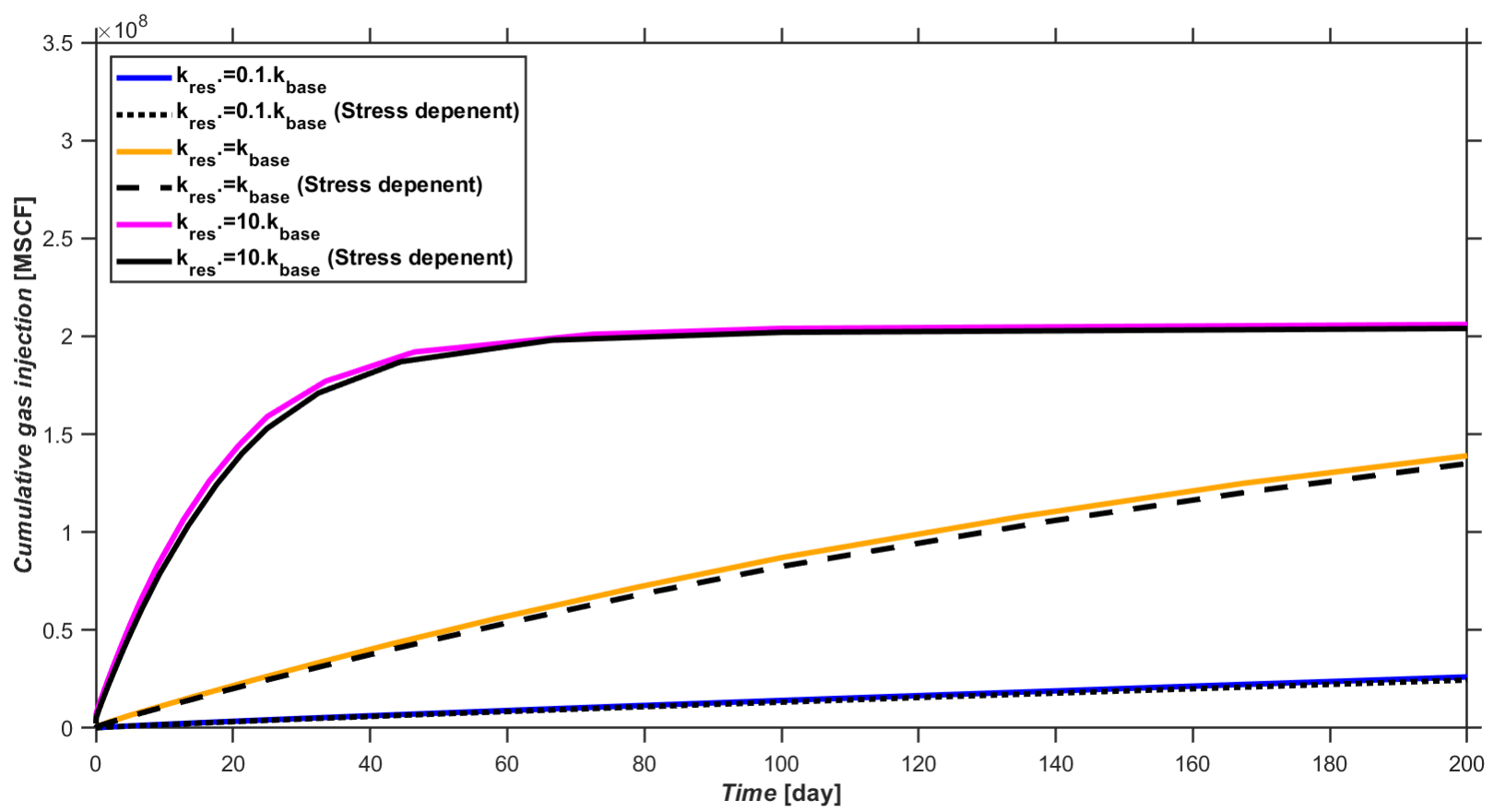

Figure 5 Cumulative gas injection (total volume of injected CO2) into the base case SGR with sensitivity to reservoir permeability and its stress dependence

It should be denoted that as it is shown in Figure 3, stress-dependent and initial permeability values are equal at reservoir pore pressure of 4000 psia. Thus, around initial pressure of the SGR which is equal to 800 psia, stress-dependent permeabilities are considerably lower than initial permeabilities of reservoir grid blocks. So, the lower cumulative $\mathrm{CO} 2$ injection of cases with stress-dependent permeability compared to base case model is due to their lower permeability values. If the SGR pressure was considerably higher than 4000 psia, total volume of injected $\mathrm{CO} 2$ for stress-dependent case would be higher the base case cumulative $\mathrm{CO} 2$ injection. However, the difference between the results for stress-dependent case and base case are slight.

Under more scrutiny, a similar analysis ran for the case in which its porosity values are half of that of base case model for both matrix and NF media of SRV and USRV zones. Result of this analysis, which is shown in Figure 6, expresses that decrease in total volume of injected CO2 due to permeability stress dependence can be more significant than the base case for a high-permeability SGR. 


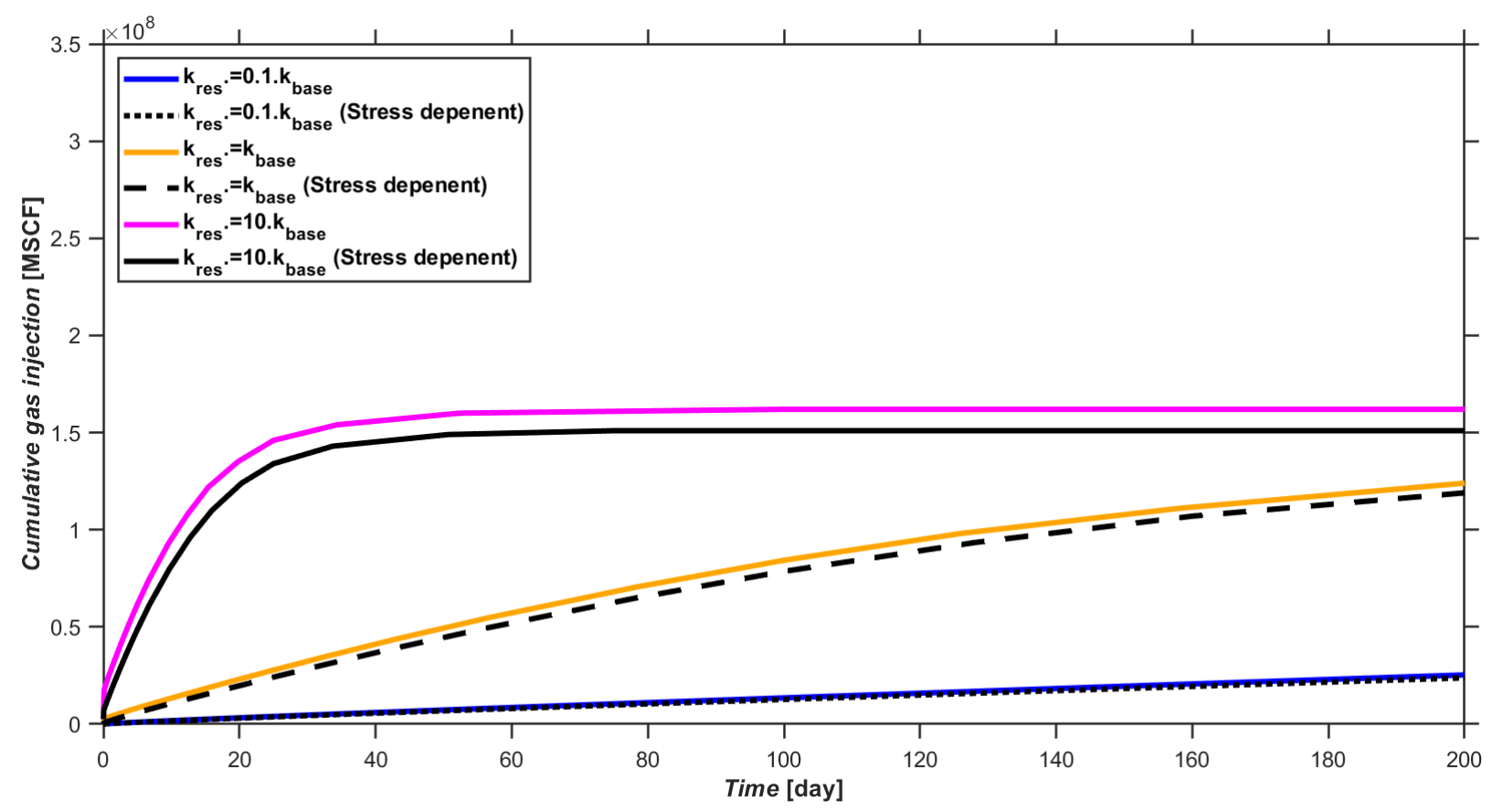

Figure 6 Cumulative gas injection (total volume of injected CO2) into the base case SGR with half porosity values with sensitivity to reservoir permeability and its stress dependence

According to Table 3, results for both cases of stress-dependent permeabilities (Figures 5 and 6) show that in case of base SGR porosity value (Figure 5), average cumulative CO2 injection for no stress-dependent permeability of 0.1 - 1 -, and 10-time base reservoir permeability are $2.5039 \mathrm{E}+6,1.5638 \mathrm{E}+7$, and $5.7986 \mathrm{E}+7$ MSCF, respectively. Also, for this case, average cumulative $\mathrm{CO} 2$ injection for stress-dependent permeability cases of $0.1-, 1-$, and 10-time base reservoir permeability are calculated as $2.2774 \mathrm{E}+6,1.4569 \mathrm{E}+7$, and $5.4908 \mathrm{E}+7 \mathrm{MSCF}$, respectively. In fact, stress-dependent permeability model has caused approximately $10 \%, 7.3 \%$, and $5.6 \%$ reduction in total amount of $\mathrm{CO} 2$ injection to the reservoir, respectively, in cases of reservoir permeabilities 0.1-, 1-, and 10-time base reservoir permeability. In addition, same approach for sensitivity analysis for the reservoir with porosity half of the base reservoir porosity (Figure 6), shows average cumulative $\mathrm{CO} 2$ injection for no stress-dependent reservoir permeabilities 0.1-, 1-, and 10-time base reservoir permeability as 2.2062E+6, 1.4130E+7, and 5.1089E+7 MSCF, respectively. Also, for stressdependent permeability values $0.1-, 1-$, and 10 -time base reservoir permeability average cumulative $\mathrm{CO} 2$ injection are $2.2062 \mathrm{E}+6,1.4130 \mathrm{E}+7$, and $5.1089 \mathrm{E}+7 \mathrm{MSCF}$, respectively. Thus, it shows that stressdependent permeability model causes almost 9\%, 10\%, and 16\% decrease in average cumulative CO2 injection to the reservoir, respectively, in cases of reservoir permeabilities $0.1-, 1-$, and 10-time base reservoir permeability. 
Table 3 Results for average cumulative CO2 injection to the SGR with/without stress-dependent permeability model

\begin{tabular}{|c|c|c|c|}
\hline \multicolumn{4}{|l|}{ High-porosity SGR (6\%) } \\
\hline Average cumulative $\mathrm{CO} 2$ injection & $k=k_{\text {base }}$ & $\mathrm{k}=0.1 \mathrm{k}_{\text {base }}$ & $k=10 k_{\text {base }}$ \\
\hline without stress dependence, MSCF & $2.5039 \mathrm{E}+6$ & $1.5638 \mathrm{E}+7$ & $5.7986 \mathrm{E}+7$ \\
\hline with stress dependence, MSCF & $2.2774 \mathrm{E}+6$ & $1.4569 \mathrm{E}+7$ & $5.4908 \mathrm{E}+7$ \\
\hline Reduction percentage of with/without stress dependence, $\%$ & 10 & 7.3 & 5.6 \\
\hline \multicolumn{4}{|l|}{ Low-porosity SGR (3\%) } \\
\hline Average cumulative $\mathrm{CO} 2$ injection & $\mathrm{k}=\mathrm{k}_{\text {base }}$ & $\mathrm{k}=0.1 \mathrm{k}_{\text {base }}$ & $\mathrm{k}=10 \mathrm{k}_{\text {base }}$ \\
\hline without stress dependence, MSCF & $2.2062 \mathrm{E}+6$ & $1.4130 \mathrm{E}+7$ & $5.1089 \mathrm{E}+7$ \\
\hline with stress dependence, MSCF & $2.2062 \mathrm{E}+6$ & $1.4130 \mathrm{E}+7$ & $5.1089 \mathrm{E}+7$ \\
\hline Reduction percentage of with/without stress dependence, \% & 9 & 10 & 16 \\
\hline
\end{tabular}

The second analysis of this study investigates the effect of gas adsorption on the CO2 injection results. As it is followed by Figure 7, same as the first analysis, effect of variation in reservoir permeability is analyzed for the base SGR model. Moreover, sensitivity of cumulative CO2 injection to gas adsorption is analyzed. As it is recognized from Figure 7, not considering gas adsorption phenomenon for each case of reservoir permeability values causes an underestimation in cumulative gas injection results. This underestimation is more considerable in high-permeability SGRs and negligible in low-permeability SGRs.

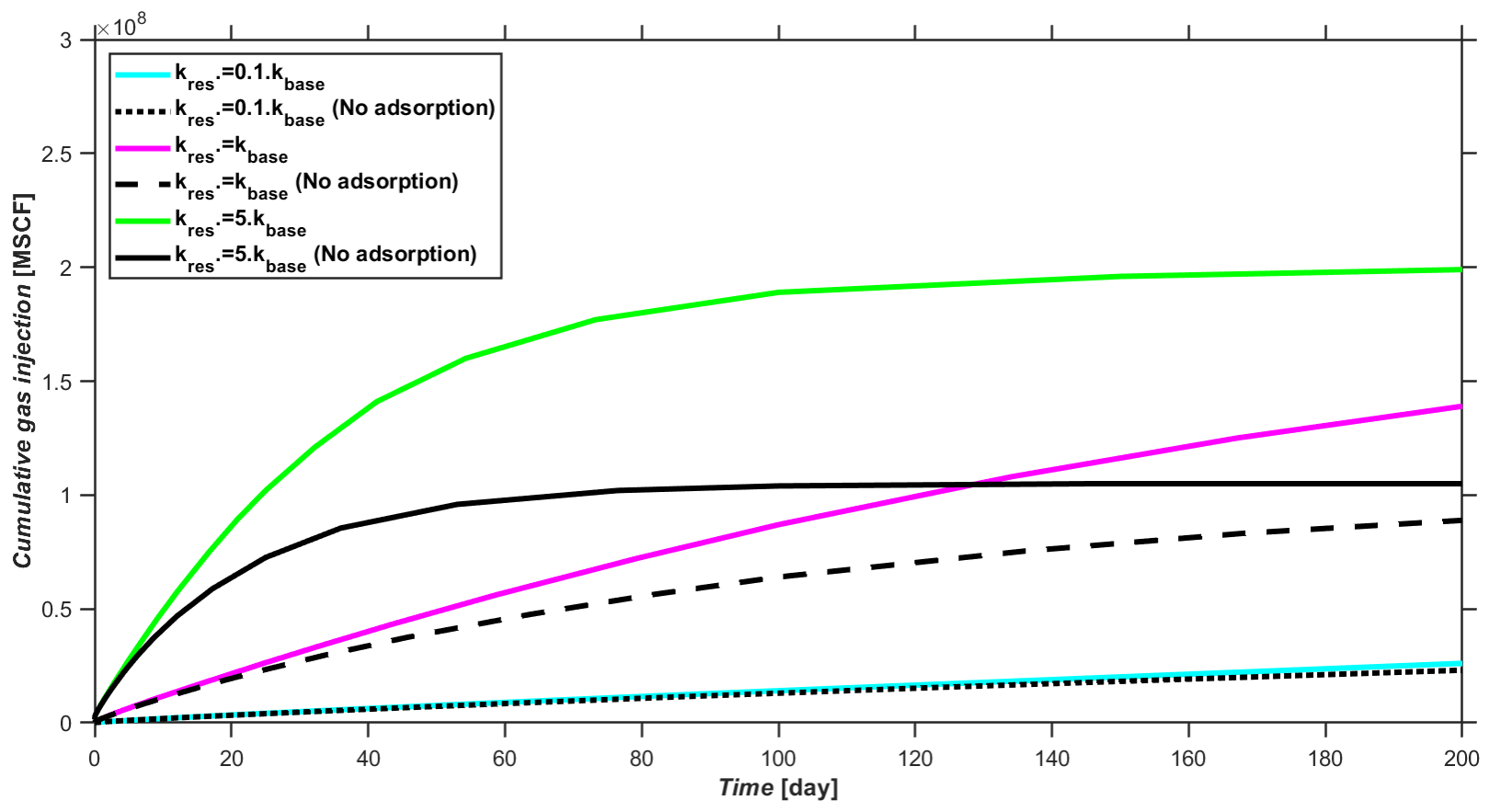

Figure 7 Cumulative gas injection (total injected CO2 volume) into the base case SGR with sensitivity to reservoir permeability and presence of gas sorption phenomenon 
Results for total injected $\mathrm{CO} 2$ volume sensitivity to reservoir permeability and gas sorption effect reveal that average cumulative CO2 injection for SGR having no sorption effect with permeability 0.1-, 1-, and 5time base reservoir permeability are 2.2871E+6, 1.2364E+7, 2.8650E+7 MSCF, respectively. Also, by considering gas adsorption/desorption ability in the reservoir, average cumulative CO2 injection for SGRs with permeability $0.1-, 1$-, and 5-time base reservoir permeability are 2.4625E+6, 1.5595E+7, and $4.2367 \mathrm{E}+7 \mathrm{MSCF}$, respectively. In other words, considering gas sorption in the SGR simulation model causes $7.7 \%, 26 \%$, and $48 \%$ increase in cumulative $\mathrm{CO} 2$ injection to reservoirs with permeability $0.1-$, 1-, and 5time base reservoir permeability, respectively.

\section{Conclusion}

The numerical simulation study with finite difference method has been performed for a CCS operation in an SGR. By considering the SGR as a large-scale sustainable material for separation of CO2 from environment, effect of several petrophysical and geochemical features of these petroleum gas reservoirs are investigated in the performance of CCS in this study. Sensitivity analyses for SGR permeability (permeability of rock matrix and NF), stress-dependent permeability, and gas sorption leads to some outstanding conclusions. Overall, the results of this study can be classified as follows:

1. The effect of stress-dependent permeability in all values for reservoir permeabilities causes a slight decrease in cumulative gas injection.

2. If SGR is high-porosity (6\%), the decrease in total volume of injected CO2 due to permeability stress dependence can be more significant than the base case for a low-permeability SGR.

3. If SGR is low-porosity (3\%), the decrease in total volume of injected $\mathrm{CO} 2$ due to permeability stress dependence can be more significant than the base case for a high-permeability SGR.

4. An underestimation in cumulative gas injection results can be seen by not considering gas adsorption phenomenon for each case of reservoir permeability values. This is more considerable in high-permeability SGRs and negligible in low-permeability SGRs. 


\section{Acronyms}

$\begin{array}{ll}\text { 3D } & \text { 3 dimensional } \\ \text { CCS } & \text { Carbon capture and sequestration } \\ \text { CH4 } & \text { Methane } \\ \text { CO2 } & \text { Carbon dioxide } \\ \text { EGR } & \text { Enhanced gas recovery } \\ \text { HF } & \text { Hydraulic fractures } \\ \text { kbase } & \text { Base case reservoir model permeability } \\ \text { LGR } & \text { Local grid refinement } \\ \text { MSCF } & \text { Thousands standard cubic feet } \\ \text { MSFHW } & \text { Multi-stage fractured horizontal well } \\ \text { NF } & \text { Natural fracture } \\ \text { NFR } & \text { Naturally fractured reservoir } \\ \text { SGR } & \text { Shale gas reservoir } \\ \text { SRV } & \text { Stimulated rock volume } \\ \text { TOC } & \text { Total organic carbon } \\ \text { USRV } & \text { Unstimulated rock volume } \\ \text { \$base } & \text { Base case reservoir model porosity }\end{array}$

\section{References}

[1] B. Metz, O. Davidson, H.C. de Coninck, M. Loos, L.A. Meyer, IPCC special report on Carbon Dioxide Capture and Storage, 2005.

[2] M. Gamil, A. Gharizadeh, F. Sartipi, A review on graphene reinforced cement composite : technical approach for ecofriendly construction, J. Constr. Mater. 1 (2019) 1-4.

[3] J. Luliano, A. Singh, F. Sartipi, Political-economical evaluation of CO2 capture in Australian building sector, J. Constr. Mater. 1 (2020) 1-10. https://doi.org/10.36756/jcm.v1.3.2.

[4] A. Todhunter, M. Crowley, F. Sartipi, K. Jegendran, Use of the by-products of post-combustion carbon capture in concrete production: Australian case study, J. Constr. Mater. 1 (2019) 1-19. https://doi.org/10.36756/jcm.v1.1.1.

[5] A.K. Shukla, Z. Ahmad, M. Sharma, G. Dwivedi, T.N. Verma, S. Jain, P. Verma, A. Zare, Advances of carbon capture and storage in coal-based power generating units in an indian context, Energies. (2020). https://doi.org/10.3390/en13164124. 
[6] S. Merey, C. Sinayuc, Analysis of carbon dioxide sequestration in shale gas reservoirs by using experimental adsorption data and adsorption models, J. Nat. Gas Sci. Eng. (2016). https://doi.org/10.1016/j.jngse.2016.02.052.

[7] J.S. Levine, I. Fukai, D.J. Soeder, G. Bromhal, R.M. Dilmore, G.D. Guthrie, T. Rodosta, S. Sanguinito, S. Frailey, C. Gorecki, W. Peck, A.L. Goodman, U.S. DOE NETL methodology for estimating the prospective CO2 storage resource of shales at the national and regional scale, Int. J. Greenh. Gas Control. (2016). https://doi.org/10.1016/j.ijggc.2016.04.028.

[8] A. Taghavinejad, M. Sharifi, E. Heidaryan, K. Liu, M. Ostadhassan, Flow modeling in shale gas reservoirs: A comprehensive review, J. Nat. Gas Sci. Eng. 83 (2020) 103535. https://doi.org/10.1016/j.jngse.2020.103535.

[9] S. Dahim, A. Taghavinejad, M. Razghandi, H. Rahimi Rigi, K. Moeini, S. Jamshidi, M. Sharifi, Pressure and Rate Transient Modeling of Multi Fractured Horizontal Wells in Shale Gas Condensate Reservoirs, J. Pet. Sci. Eng. 185 (2020) 106566. https://doi.org/10.1016/j.petrol.2019.106566.

[10] L. Langmuir, The Adsorption of Gases on Plane Surfaces of Glass, Mica and Platinum, J. Am. Chem. Soc. 40 (1918) 1361-1403.

[11] R.O. Bello, R.A. Wattenbarger, RATE TRANSIENT ANALYSIS IN SHALE GAS RESERVOIRS WITH TRANSIENT LINEAR BEHAVIOR, Texas A\&M University, 2009.

[12] R.M. Bustin, A.M.M. Bustin, X. Cui, D.J.K. Ross, V.S. Murthy -Pathi, Impact of shale properties on pore structure and storage characteristics, SPE Gas Prod. Conf. (2008).

[13] T.H. Kim, S.S. Park, K.S. Lee, Modeling of $\mathrm{CO} 2$ injection considering multi-component transport and geomechanical effect in shale gas reservoirs, in: Soc. Pet. Eng. - SPE/IATMI Asia Pacific Oil Gas Conf. Exhib. APOGCE 2015, 2015. https://doi.org/10.2118/176174-ms.

[14] C. Guo, J. Wang, M. Wei, X. He, B. Bai, Multi-stage fractured horizontal well numerical simulation and its application in tight shale reservoirs, Soc. Pet. Eng. - SPE Russ. Pet. Technol. Conf. (2015). https://doi.org/10.2118/176714-ms.

[15] B. van der Meer, Carbon dioxide storage in natural gas reservoirs, Oil Gas Sci. Technol. 60 (2005) 527-536. https://doi.org/10.2516/ogst:2005035.

[16] R. Khosrokhavar, S. Griffiths, K.H. Wolf, Shale Gas Formations and Their Potential for Carbon Storage: Opportunities and Outlook, Environ. Process. 1 (2014) 595-611. https://doi.org/10.1007/s40710014-0036-4.

[17] A. Kalantari-Dahaghi, Numerical simulation and modeling of enhanced gas recovery and CO 2 sequestration in shale gas reservoirs: A feasibility study, Soc. Pet. Eng. - SPE Int. Conf. CO2 Capture, Storage, Util. 2010. (2010) 533-550. https://doi.org/10.2118/139701-ms.

[18] J. Huang, T. Jin, M. Barrufet, J. Killough, Evaluation of CO2 injection into shale gas reservoirs considering dispersed distribution of kerogen, Appl. Energy. 260 (2020) 114285. https://doi.org/10.1016/j.apenergy.2019.114285. 
[19] Y. Sun, S. Li, R. Sun, X. Liu, H. Pu, J. Zhao, Study of CO2enhancing shale gas recovery based on competitive adsorption theory, ACS Omega. 5 (2020) 23429-23436. https://doi.org/10.1021/acsomega.0c03383.

[20] H.T. Schaef, C.L. Davidson, A.T. Owen, Q.R.S. Miller, J.S. Loring, C.J. Thompson, D.H. Bacon, V.A. Glezakou, B.P. McGrail, CO2 utilization and storage in shale gas reservoirs: Experimental results and economic impacts, Energy Procedia. 63 (2014) 7844-7851. https://doi.org/10.1016/j.egypro.2014.11.819.

[21] A. Raza, R. Gholami, R. Rezaee, C.H. Bing, R. Nagarajan, M.A. Hamid, CO2 storage in depleted gas reservoirs: A study on the effect of residual gas saturation, Petroleum. 4 (2018) 95-107. https://doi.org/10.1016/j.petlm.2017.05.005.

[22] M.D. White, B.J. McPherson, R.B. Grigg, W. Ampomah, M.S. Appold, Numerical simulation of carbon dioxide injection in the western section of the farnsworth unit, Energy Procedia. 63 (2014) 78917912. https://doi.org/10.1016/j.egypro.2014.11.825.

[23] S.S.H. Boosari, U. Aybar, M.O. Eshkalak, Carbon Dioxide Storage and Sequestration in Unconventional Shale Reservoirs, J. Geosci. Environ. Prot. 03 (2015) 7-15. https://doi.org/10.4236/gep.2015.31002.

[24] A. Lekić, L. Jukić, M. Arnaut, M. Macenić, Simulation of CO2 injection in a depleted gas reservoir: A case study for upper miocene sandstone, northern Croatia, Rud. Geol. Naft. Zb. 34 (2019) 139-149. https://doi.org/10.17794/rgn.2019.1.12.

[25] E.M. Winter, P.D. Bergman, Availability of depleted oil and gas reservoirs for disposal of carbon dioxide in the United States, Energy Convers. Manag. 34 (1993) 1177-1187. https://doi.org/10.1016/01968904(93)90067-K.

[26] M.D. Aminu, S.A. Nabavi, C.A. Rochelle, V. Manovic, A review of developments in carbon dioxide storage, 2017. https://doi.org/10.1016/j.apenergy.2017.09.015.

[27] Z. Chen, X. Liao, X. Zhao, X. Li, Appraising carbon geological-storage potential in unconventional reservoirs: Engineering-parameters analysis, SPE Reserv. Eval. Eng. 21 (2018) 476-488. https://doi.org/10.2118/189442-pa.

[28] D.A. Edwards, N. Cheng, T.P. Dombrowsky, G. Bowen, H. Nasvik, Representing hydraulic fractures using a multilateral, multisegment well in simulation models, Soc. Pet. Eng. - SPE Reserv. Simul. Symp. 2013. 2 (2013) 939-951. https://doi.org/10.2118/163644-ms.

[29] A. Shirbazo, J. Fahimpour, B. Aminshahidy, A new approach to finding effective parameters controlling the performance of multi-stage fractured horizontal wells in low-permeability heavy-oil reservoirs using RSM technique, J. Pet. Explor. Prod. Technol. 10 (2020) 3569-3586. https://doi.org/10.1007/s13202-020-00931-3.

[30] M.T. Baig, S. Alnuaim, M.H. Rammay, Productivity increase estimation for multi stage fracturing in horizontal wells for tight oil reservoirs, Soc. Pet. Eng. - SPE Saudi Arab. Sect. Annu. Tech. Symp. Exhib. (2015). https://doi.org/10.2118/178030-ms.

[31] X. Xue, C. Yang, T. Onishi, M.J. King, A. Datta-Gupta, Modeling hydraulically fractured shale wells using the fast marching method with local grid refinements LGRs and embedded discrete fracture model 
EDFM, in: Soc. Pet. Eng. - SPE Reserv. Simul. Conf. 2019, RSC 2019, 2019. https://doi.org/10.2118/193822ms.

[32] S.. Abdelmoneim, R. Rabee, A.. Shehata, Modeling hydraulic fractures in finite difference simulators using amalgam LGR ( Local Grid Refinement ), in: SPE, 2012.

[33] A. Danesh, PVT and Phase Behaviour Of Petroleum Reservoir Fluids, Elsevier Science, 1998.

[34] H. Kazemi, L.S. Merrill-Jr, K.L. Porterfield, P.R. Zeman, Numerical simulation of water-oil flow in naturally fractured reservoirs, SPE J. 16 (1976) 317-326.

[35] J.R. Seidle, L.G. Huitt, Experimental measurement of coal matrix shrinkage due to gas desorption and implications for cleat permeability increases, Int. Meet. Pet. Eng. . (1995). 